\title{
Tick Distribution and Detection of Babesia and Theileria Species in the East and South regions of Kazakhstan
}

\section{Chunli Sang}

Department of Basic Medicine, School of Medicine, Shihezi University, Shihezi, Xinjiang Uygur Autonomous Region 832002, People's Republic of China

\section{Meihua Yang}

Department of Forestry, School of Agriculture, Shihezi University, Shihezi, Xinjiang, Uygur Autonomous Region 832000, People's Republic of China

\section{Bin Xu}

National Institute of Parasitic Diseases, Chinese Center for Disease Control and Prevention, WHO Collaborating Center for Tropical Diseases, Key Laboratory of Parasitology and Vector Biology of the Chinses Ministry of Health, Shanghai 200025, China

\section{Guangyuan Liu}

State Key Laboratory of Veterrinary Etiological Biology, Key Laboratory of Veterinary Parasitology of Gansu Province, Lanzhou Veterinary Research Institute, Chinese Academy of Agricultural Science, Xujiaping 1\#, Lanzhou, Gansu 730046, People's Republic of China

\section{Yicheng Yang}

School of Medicine,Shihezi University, Xinjiang Uygur Autonimous Region 832002, People's Republic of China

\section{Bolatkhan Makhatov}

Department of Anatomy, Physilogy and Biochemistry, Kazakh National Agrarian University, Almaty, Kazakstan.

\section{Wurelihazi Hazihan}

School of Animal Science and Technology, Shihezi University, Shihezi, Xinjiang Uygur Autonomous Region 832000, People's Republic of China

\section{Sándor Hornok}

Department of Parasitology and Zoology, University of Veterinary Medicine, Budapest, Hungary Yuan-Zhi Wang ( $\square$ wangyuanzhi621@126.com)

Shihezi University

\section{Research}

Keywords: Ticks, Babesia, Theileria, Kazakhstan 
Posted Date: June 10th, 2020

DOl: https://doi.org/10.21203/rs.3.rs-33830/v1

License: (c) (i) This work is licensed under a Creative Commons Attribution 4.0 International License. Read Full License 


\section{Abstract}

Background: Piroplasmosis, caused by Theileria and Babesia species, is an economically important tickborne disease worldwide. However, little is known about the presence of Babesia spp. and Theileria spp. in ticks from different host species in Kazakhstan.

Method: We collected adult ticks at 26 sampling sites in 16 districts in the East and South regions of Kazakhstan during 2016 - 2019. Tick species were identified according to morphological and molecular characteristics. Two fragments of the $18 S$ ribosomal RNA (18S rRNA) were used to determine the species of piroplasms. The genotype characteristics of Babesia caballi and Theileria equi were analyzed further.

Results: A total of 6107 adult ticks were collected, including 2920 Dermacentor marginatus, 1442 Argas persicus, 903 Hyalomma asiaticum, 464 Hyalomma scupense, 225 Hyalomma anatolicum, 122 Rhipicephalus turanicus, 16 Haemaphysalis erinacei and 15 Dermacentor reticulatus. In these ticks five species of piroplasms, i.e. Babesia occultans, Babesia caballi, Theileria ovis, Theileria annulata and Theileria equi, were detected. Theileria equi and Babesia caballi belonged to their $\mathrm{E}$ and A genotype, respectively.

Conclusions: Apart from Dermacentor marginatus, three Hyalomma species predominate among ticks infesting herbivorous livestock in East and South regions of Kazakhstan. 16S ribosomal DNA (16S rDNA) phylogenic analysis showed that several tick species in Kazakhstan, as exemplified by $D$. marginatus and Ha. erinacei, were clustered together with conspecific ticks reported from China. Babesia occultans was found for the first time in D. marginatus in Kazakhstan. Altogether five piroplasm species were detected, indicating that enhanced control measures are necessary to prevent piroplasm infection of domestic animals in this region.

\section{Background}

Kazakhstan, located in Central Asia, covers 2.72 million square kilometers and borders five countries including China, the Russian Federation, Kyrgyzstan, Uzbekistan and Turkmenistan. Five border oblasts in the East and South regions of Kazakhstan, namely Kyzylorda, South Kazakhstan, Jambyl, Almaty and East Kazakhstan, cover about one-third of Kazakhstan, with an east-west span of approximately 2,000 kilometers, and border Kyrgyzstan to the South and Xinjiang Uygur Autonomous Region (XUAR, northwestern China) to the East.

At least thirteen tick species have been reported from Kazakhstan, including Hyalomma asiaticum, Hyalomma anatolicum, Hyalomma scupense, Hyalomma marginatum, Haemaphysalis punctata, Haemaphysalis sulcata, Dermacentor daghestanicus, Dermacentor marginatus, Dermacentor niveus, Dermacentor reticulatus, Ixodes persulcatus, Rhipicephalus turanicus, Rhipicephalus pumilio and Rhipicephalus (Boophilus) calcaratus [1-4]. Unfortunately, there have been few comprehensive reports regarding the distribution and abundance of ticks in Kazakhstan, especially in the East and South regions. 
Historically, tick-borne diseases have always represented important public health issues in Central Asia. Among the others, tick-borne encephalitis, rickettsial diseases, $Q$ fever and Crimean Congo hemorrhagic fever are known to occur in Kazakhstan [3-6]. Piroplasms (Apicomplexa: Piroplasmida) are tick-borne parasitic protozoa, most of which belong to the genera Theileria and Babesia [7]. A number of these parasites are highly pathogenic for cattle, horses, dogs, sheep, camels and in some cases, even to humans, as they may cause high fever, lethargy, anorexia, peripheral edema, petechiation of the mucous membranes, hemolysis, tachycardia and pigmenturia $[8,9]$. Bovine theileriosis caused by Theileria annulata and equine piroplasmosis caused by Theileria equi were reported in Kazakhstan [10-12]. However, the detection of Babesia and Theileria species in ticks from other livestock and wildlife species is still poorly known in this country, especially in East and South regions.

In the present study, the distribution and abundance of tick species were investigated in the East and South regions of Kazakhstan. These ticks were also screened for the presence of Babesia and Theileria DNA. In addition, genotype characteristics of T. equi and Babesia caballi in ticks of horses were evaluated.

\section{Methods}

\section{Tick sampling and morphological identification}

From March to May during 2016 - 2019, contemporaneously with the peak activities of adult ticks in Kazakhstan, ticks were collected from their hosts and in the environment at 26 sampling sites in East Kazakhstan (8), Almaty (9), Jambyl (2), Southern Kazakhstan (6) and Kyzylorda (1). Off-host ticks were collected by the dragging-flagging and artificial trapping methods $[13,14]$. Engorged ticks were sampled over the entire body of each animal including cattle, horses, sheep, camels, shepherd dogs, hedgehogs and chickens [15]. Data of all specimens were recorded, including date and location of collection, host species (if relevant) and individual number. All ticks were identified morphologically according to previous reports $[16,17]$.

\section{DNA extraction and molecular identification of ticks}

After detailed morphological analysis, the genomic DNA was extracted from 209 ticks individually (2 to 40 individuals per tick species representing each sampling site) with the TIANamp Genomic DNA Kit (TIANGEN, Beijing, China). These DNA extracts were used for molecular taxonomic analysis of the $16 S$ rDNA gene [18].

\section{Molecular and phylogenetic analyses of Babesia and Theileria species}

The presence of Babesia and Theileria species was screened with a PCR amplifying two fragments (487bp and 438bp) of the $18 S$ ribosomal RNA (18S rRNA) gene, using the primers BJ1/BN2 [19] and PIRO-A/B [20]. Sequence-confirmed Babesia occultans and Theileria ovis DNA amplified in our laboratory and double distilled water were used as positive and negative controls, respectively [21]. In addition, 
samples positive for $B$. caballi and $T$. equi were evaluated further by amplifying longer the $18 S$ rRNA gene fragments $(\nabla 1,380 \mathrm{bp}$ for $B$. caballi and $\otimes 1470 \mathrm{bp}$ for $T$. equi). Nucleotide sequences of the primers used for the identification of piroplasm and tick species were shown in Appendix Table S1. PCR products were purified using the TIANgel Midi Purification Kit (TIANGEN, Beijing, China) and cloned into the pGEM-T Easy vector and subjected to sequencing. The sequences obtained here were compared to others deposited in GenBank with the BLASTn programme (http://www.ncbi.nlm.nih.gov/BLAST/). Phylogenic trees were constructed using the Maximum Likelihood method with MEGA 7.0 software [22].

\section{Results}

A total of 6107 adult ticks, belonging to five genera and eight species (2920 D. marginatus, $1442 \mathrm{~A}$. persicus, 903 Hy. asiaticum, 464 Hy. scupense, 225 Hy. anatolicum, 122 Rh. turanicus, 16 Haemaphysaliserinacei and 15 D. reticulatus), were collected in five border oblasts of Kazakhstan (Fig. 1 and Appendix Table S2). D. marginatus $(64.29 \%, 2920 / 4542)$ was the most abundant species on the herbivorous mammals, followed by Hy. asiaticum (17.53\%, 796/4542), Hy. scupense (10.22\%, 464/4542), Hy. anatolicum $(4.95 \%, 225 / 4542)$. A. persicus was collected from chicken and Ha. erinacei from hedgehog.

Piroplasms were molecularly detected in 698 out of 6107 sampled ticks by amplifying 487 bp and 438 bp $18 S$ rRNA fragments. Among these, 1.43\% (10/698) and 3.44\% (24/698) of samples were positive for Babesia and Theileria species, respectively. Based on sequence comparisons, two Babesia species ( $B$. occultans and B. caballi) and three Theileria species (T. ovis, T. annulata and T. equi) were identified (Table 1, Fig. 2 and Appendix Table S3). Phylogenetic analyses using 18S rRNA fragments revealed that T. equi belonged to genotype $\mathrm{E}$ and B. caballi to genotype A (Fig. 3A and 3B).

Table 1 Detection of Babesia spp. and Theileria spp. in ticks sampled from the East and South regions of Kazakhstan. 


\begin{tabular}{|c|c|c|c|c|c|}
\hline Oblast & District & Tick species & Origination & Number & $\begin{array}{l}\text { Babesia/ Theileria } \\
\text { species, No. } \\
\text { positive (\%) }\end{array}$ \\
\hline \multirow[t]{6}{*}{ Almaty } & \multirow{2}{*}{$\begin{array}{l}\text { Balkhash } \\
\text { County } \\
\text { (BH) }\end{array}$} & Hyalommaaiaticum & Off host & 47 & $\begin{array}{l}\text { Babesia caballi, } 1 \\
(2.13 \%)\end{array}$ \\
\hline & & Haemaphysaliserinacei & Hedgehog & 16 & 0 \\
\hline & $\begin{array}{l}\text { Shagan } \\
\text { City (SN) }\end{array}$ & Rhipicephalusturanicus & Goat & 24 & $\begin{array}{l}\text { Theileriaannulata, } \\
5(33.33 \%)\end{array}$ \\
\hline & $\begin{array}{l}\text { Usharal } \\
\text { County } \\
\text { (UR) }\end{array}$ & Hyalomma scupense & Cattle & 14 & 0 \\
\hline & $\begin{array}{l}\text { Ushtobe } \\
\text { County } \\
\text { (UT) }\end{array}$ & $\begin{array}{l}\text { Dermacentor } \\
\text { marginatus }\end{array}$ & Horse & 22 & 0 \\
\hline & $\begin{array}{l}\text { Karabulak } \\
\text { County } \\
\text { (KL) }\end{array}$ & Dermacentormarginatus & Horse & 10 & $\begin{array}{l}\text { Babesia caballi, } 1 \\
(10 \%) \text { Theileria } \\
\text { equi, } 2(20 \%)\end{array}$ \\
\hline \multirow{3}{*}{$\begin{array}{l}\text { East } \\
\text { Kazakhstan }\end{array}$} & \multirow{2}{*}{$\begin{array}{l}\text { Zaysan } \\
\text { County } \\
\text { (ZS) }\end{array}$} & Hyalomma scupense & Cattle & 48 & 0 \\
\hline & & Dermacentormarginatus & Cattle & 12 & 0 \\
\hline & $\begin{array}{l}\text { Shyghys } \\
\text { qazaqstan } \\
\text { City (SQ) }\end{array}$ & Dermacentormarginatus & Cattle & 15 & 0 \\
\hline \multirow[t]{6}{*}{$\begin{array}{l}\text { South } \\
\text { Kazakhstan }\end{array}$} & \multirow[t]{3}{*}{$\begin{array}{l}\text { Chimkent } \\
\text { City (CK) }\end{array}$} & Dermacentormarginatus & Cattle & 36 & $\begin{array}{l}\text { Babesia caballi, } 2 \\
(5.56 \%)\end{array}$ \\
\hline & & & Horse & 24 & $\begin{array}{l}\text { Theileria equi, } 6 \\
(25 \%)\end{array}$ \\
\hline & & Argas persicus & Chicken & 102 & 0 \\
\hline & \multirow{2}{*}{$\begin{array}{l}\text { Saryagash } \\
\text { County } \\
\text { (SG) }\end{array}$} & Dermacentormarginatus & Cattle & 159 & \multirow{2}{*}{$\begin{array}{l}\text { Babesia caballi, } 4 \\
(2.30 \%) \text { Theileria } \\
\text { annulata, } 4 \\
(2.30 \%) \text { Babesia } \\
\text { occultans, } 2 \\
(1.45 \%)\end{array}$} \\
\hline & & Dermacentorreticulatus & Horse & 15 & \\
\hline & $\begin{array}{l}\text { Kazygurt } \\
\text { County } \\
\text { (KG) }\end{array}$ & Rhipicephalus turanicus & Dog & 24 & $\begin{array}{l}\text { Theileria } \\
\text { annulata, } 4 \\
(16.67 \%) \\
\text { Theileria ovis, } 1 \\
(4.17 \%)\end{array}$ \\
\hline \multirow[t]{2}{*}{ Zhambyl } & Merki (MK) & Dermacentormarginatus & Cattle & 20 & 0 \\
\hline & $\begin{array}{l}\text { Lugovoy } \\
\text { (LG) }\end{array}$ & Hyalomma anatolicum & Cattle & 40 & 0 \\
\hline
\end{tabular}




\section{Discussion}

In the present study, eight tick species were found in five border oblasts in the East and South regions of Kazakhstan. To our knowledge, the following records had been reported previously in this area: I. persulcatus in East Kazakhstan, Hy. asiaticum, Rh. turanicus, Hy. scupense, D. niveus and D. marginatus in Kyzylorda, Hy. asiaticum and Hy. scupense in Jambyl, Hy. anatolicum, Hy. asiaticum, Ha. punctata, Ha. sulcate and Hy. scupense in South Kazakhstan, Hy. asiaticum, Hy. scupense, I. persulcatus, Ha. punctata, $D$. marginatus and $D$. reticulatus in Almaty region $[1,3,23]$. This implies that $D$. marginatus and $H y$. anatolicum were detected for the first time in Jambyl, and further four species ( $D$. marginatus, $D$. reticulatus, Rh. turanicus and A. persicus) in South Kazakhstan, extending our knowledge on tick species in these regions. Compared with previous studies, D. marginatus and $H y$. scupense can be considered as emerging tick species in East Kazakhstan, similarly to Rh. turanicus in Almaty.

Southeastern Kazakhstan and Northwestern China share 1,760 km borderline. In the present study, $D$. marginatus and $\mathrm{Hy}$. asiaticum were the most abundant tick species in five border oblasts of Kazakhstan. Interestingly, D. marginatus and $H y$. asiaticum were also dominant tick species in the neighboring Xinjiang Uygur Autonomous Region (XUAR, northwestern China) [24]. Furthermore, the phylogenetic tree based on $16 S$ rDNA sequences showed that $D$. marginatus ticks in Almaty, Jambyl and South Kazakhstan clustered together with those from XUAR (GenBank: MF002564). In addition, Hy. asiaticum (MN907445) in Almaty represented the same phylogenetic group as ticks from Turkmenistan (KU13042), Turkey (MG418675) as well as XUAR of China (MF973043) (Fig. 4). Hy. scupense, however, showed different abundances on domestic animals in Southeastern Kazakhstan compared to Northwestern China. According to the present results, this species is widely distributed in East Kazakhstan and Almaty on cattle and goats, while it is rare in XUAR [24].

1. B. occultans was firstly described from Hyalomma rufipes in 1981 in South Africa [25]. Subsequently, it was found in engorged rufipes, Hyalomma truncatum, Hyalomma impressum, Hyalomma marginatum and Hyalomma impeltatum ticks in 1984 in Nigeria [26]. For a long time, the distribution of $B$. occultans was believed to be confined to sub-Saharan Africa. However, in 2017 it was shown to be present in Dermacentornuttalli in XUAR [21]. Here B. occultans detected for the first time in $D$. marginatus ticks in Kazakhstan clustered phylogenetically with B. occultans (MF120939) reported from Jimunai County of XUAR (Fig. 2). Taken together, in this study five species of piroplasms, i.e. $B$. occultans, B. caballi, T. ovis, T. annulata and T. equi were detected in South Kazakhstan, suggesting that enhanced control measures are necessary to prevent piroplasm infection of domestic animals in this region. 
The $18 S$ rRNA gene is widely used as a genetic marker for phylogenetic analyses of piroplasms [27]. Previous studies reported that $T$. equi genotype $E$ was associated with fatal cases of equine piroplasmosis in Greece and Spain $[28,29]$. Although increasing amounts of data on equine piroplasmosis had become available from Spain, Mongolia, Egypt and China [28, 30-32], no studies aimed to examine the genotype of $T$. equi and $B$. caballi in Kazakhstan. Here, phylogenetic analysis showed that $B$. caballi in Almaty and South Kazakhstan belonged to genotype A, which was also present in China (MH651221), South Africa (EU642512), Spain (AY309955) and Brazil (KY952235). At the same time, T. equi (MN857679 and MN857677) from South Kazakhstan clustered into genotype $E$ of this species, together with isolates from Spain (AY534882), China (MH651213 and KF559357) and South Korea (HM229407).

\section{Conclusions}

In this study, eight tick species and five piroplasm species were found in five border oblasts in the East and South regions of Kazakhstan. $16 S$ ribosomal DNA phylogenic analysis showed that several tick species from Kazakhstan, such as D. marginatus and Ha. erinacei, clustered with conspecific ticks from China. B. occultans was found for the first time in D. marginatus in Kazakhstan. Genotype E of $T$. equi and genotype $A$ of $B$. caballi were shown to occur in the study region.

\section{Abbreviations}

18S rRNA: $18 S$ ribosomal RNA; $16 S$ rDNA: 16 S ribosomal DNA; XUAR: Xinjiang Uygur Autonomous Region.

\section{Declaration}

\section{Acknowledgements}

The authors thank the contributions by the staff at the Department of Anatomy, Physiology and Biochemistry, and the Department of Food Engineering, Kazakh National Agrarian University, Almaty, Kazakhstan.

\section{Authors' contributions}

$\mathrm{CS}, \mathrm{MY}, \mathrm{BX}$ and $\mathrm{YW}$ conceived and designed the study, and writing the manuscript. CS, GL, YY, BM and WH performed the experiments, analyzed the data. SH critically revised the manuscript. All authors read and approved the final manuscript.

\section{Funding}

This research was supported in part by the National Key Research \& Development Programme of China (2018ZX10101002-007 and 2018ZX10101002-003) and National Natural Science Foundation of China (81960379 and 31960709). 
Availability of data and materials

Data supporting the conclusions of this article are included within the article. The datasets used and analyzed during the present study are available from the corresponding author upon reasonable request.

\section{Ethics and consent to participate}

Not applicable.

\section{Consent for publication}

Not applicable.

\section{Competing interests}

The authors declare that they have no competing interests.

\section{Author details}

${ }^{1}$ Department of Basic Medicine, School of Medicine, Shihezi University, Shihezi, Xinjiang Uygur Autonomous Region 832002, People's Republic of China. ${ }^{2}$ Department of Forestry, School of Agriculture, Shihezi University, Shihezi, Xinjiang, Uygur Autonomous Region 832000, People's Republic of China.

${ }^{3}$ National Institute of Parasitic Diseases, Chinese Center for Disease Control and Prevention, WHO Collaborating Center for Tropical Diseases, Key Laboratory of Parasitology and Vector Biology of the Chinese Ministry of Health, Shanghai 200025, China. ${ }^{4}$ State Key Laboratory of Veterinary Etiological Biology, Key Laboratory of Veterinary Parasitology of Gansu Province, Lanzhou Veterinary Research Institute, Chinese Academy of Agricultural Science, Xujiaping 1\#, Lanzhou, Gansu 730046, People's Republic of China. ${ }^{5}$ Emergency Department, Shihezi City People's Hospital, Shihezi, Xinjiang Uygur Autonomous Region 832000, People's Republic of China. ${ }^{6}$ Department of Anatomy, Physiology and Biochemistry, Kazakh National Agrarian University, Almaty, Kazakhstan. ${ }^{7}$ School of Animal Science and Technology, Shihezi University, Shihezi, Xinjiang Uygur Autonomous Region 832000, People's Republic of China. ${ }^{8}$ Department of Parasitology and Zoology, University of Veterinary Medicine, Budapest, Hungary.

\section{References}

1. Nurmakhanov T, Sansyzbaev Y, Atshabar B, Deryabin P, Kazakov S, Zholshorinov A, et al. CrimeanCongo haemorrhagic fever virus in Kazakhstan (1948-2013). Int J Infect Dis. 2015;38:19-23.

2. Hay J, Yeh KB, Dasgupta D, Shapieva Z, Omasheva G, Deryabin P, et al. Biosurveillance in Central Asia: Successes and Challenges of Tick-Borne Disease Research in Kazakhstan and Kyrgyzstan. Front Public Health. 2016;4:4.

3. Turebekov N, Abdiyeva K, Yegemberdiyeva R, Dmitrovsky A, Yeraliyeva L, Shapiyeva Z, et al. Prevalence of Rickettsia species in ticks including identification of unknown species in two regions in Kazakhstan. Parasit Vectors. 2019;12(1):197. 
4. Yashina L, Petrova I, Seregin S, Vyshemirskii O, Lvov D, Aristova V, et al. Genetic variability of Crimean-Congo haemorrhagic fever virus in Russia and Central Asia. J Gen Virol. 2003;84(Pt 5):1199206.

5. Pchelkina AA, Zhmabva ZM, Zubkova RI. Q Fever in Northern Kazakhstan. Zh Mikrobiol Epidemiol Immunobiol. 1956;27(11):32.

6. Maukayeva S, Karimova S. Tick-Borne Encephalitis in Kazakhstan: A case report. Erciyes Med J. 2020;42(2):226-8.

7. Tian ZC, Liu GY, Yin H, Luo JX, Guan GQ, Luo J, et al. RPS8-a new informative DNA marker for phylogeny of Babesia and Theileria parasites in China. PLoS One. 2013;8(11):e79860.

8. Scoles GA, Ueti MW. Vector ecology of equine piroplasmosis. Annu Rev Entomol. 2015;60:561-80.

9. Uilenberg G. Babesia-a historical overview. Vet Parasitol. 2006;138(1-2):3-10.

10. Tutushin MI. Distribution and seasonal and age variation of bovine theileriasis in the south of Kazakhstan. Vostochnoe Obreve tdelenie VASKhNIL. 1981;130-4.

11. Iskakov I. Theileriasis of cattle. Veterinariya. 1968.

12. Tselishcheva LM. Experiments in Transmission of Bovine Thelleriasis by Means of Hyalomma Ticks. Sovetskaya Veterinariya. 1940;11/12:31-5.

13. Zhang GL, Zheng Z, Sun X, Liu XM, Liu R, Hai-Long LI. A survey of tick species and its distribution with the landscape structure in Xinjiang. Chin J Vector Biol \& Control. 2016;27(5):432-5.

14. Tsunoda T, Kasuga S, Amano H. Estimation of the density of nymphs of the bush tick, Haemaphysalis longicornis (Acari: Ixodidae), by the catch effort method. Exp Appl Acarol. 2004;32(1/2):69-78.

15. Wang Y-Z, Mu L-M, Zhang K, Yang M-H, Zhang L, Du J-Y, et al. A broad-range survey of ticks from livestock in Northern Xinjiang: changes in tick distribution and the isolation of Borrelia burgdorferi sensu stricto. Parasites \& Vectors. 2015;8(1):449.

16. Walker AR, Bouattour A, Camicas JL, Estrada-Pena A, Preston PM. Ticks of Domestic Animals in Africa: a guide to identification of species. 2nd ed: Bioscience Reports, Edinburgh; 2003.

17. Estrada-Pena A, Bouattour A, Camicas J-L, Walker AR. Ticks of domestic animals in the Mediterranean region: a guide to identification of species: University of Zaragoza; 2004.

18. Black WC, Piesman J. Phylogeny of hard- and soft-tick taxa (Acari: Ixodida) based on mitochondrial $16 S$ rDNA sequences. Proc Natl Acad Sci U S A. 1994;91(21):10034-8.

19. Farkas R, Takacs N, Hornyak A, Nachum-Biala Y, Hornok S, Baneth G. First report on Babesia cf. microti infection of red foxes (Vulpes vulpes) from Hungary. Parasit Vectors. 2015;8(1):55.

20. Sun Y, LG, Yang LW, Xu RM, Yu YX. Multiple infections of tick-borne pathogens in Ixodespersulcatus collected from forests in Heilongjiang province. Acta Parasitologica Et Medica Entomologica Sinica. 2007;14(4):231-40.

21. Song R, Wang Q, Guo F, Liu X, Song S, Chen C, et al. Detection of Babesia spp., Theileria spp. and Anaplasma ovis in Border Regions, northwestern China. Transbound Emerg Dis. 2018;65(6):1537-44. 
22. Kumar S, Stecher G, Tamura K. MEGA7: Molecular Evolutionary Genetics Analysis Version 7.0 for Bigger Datasets. Mol Biol Evol. 2016;33(7):1870-4.

23. Egemberdieva R, Dmitrovskiy A, Eraliyeva L, Turebekov N, Abdiyeva K, Oradova A, et al., editors. Tickborne infectious disease in the Republic of Kazakhstan. European Congress of Clinical Microbiology \& Infectious Diseasess; Barcelona, Spain, 10 May 2014.

24. Sheng J, Jiang $M$, Yang $M, B o X$, Zhao S, Zhang $Y$, et al. Tick distribution in border regions of Northwestern China. Ticks Tick Borne Dis. 2019;10(3):665-9.

25. JS G, AJ DV. Studies on a bovine Babesia transmitted by Hyalomma marginatum rufipes Koch, 1844. Onderstepoort J Vet Res. 1981;48(4):215-23.

26. $00 \mathrm{D}, \mathrm{A}$ A. The presence of kinetes of a Babesia species in the haemolymph smears of engorged Hyalomma ticks in Nigeria. Vet Parasitol 1984;17(1):41-6.

27. Hunfeld KP, Hildebrandt A, Gray JS. Babesiosis: Recent insights into an ancient disease. Int J Parasitol. 2008;38(11):1219-37.

28. Nagore D, García-Sanmartín J, García-Pérez AL, Juste RA, Hurtado A. Detection and identification of equine Theileria and Babesia species by reverse line blotting: epidemiological survey and phylogenetic analysis. Vet Parasitol. 2004;123(1-2):41-54.

29. Kouam MK, Kantzoura V, Masuoka PM, Gajadhar AA, Theodoropoulos G. Genetic diversity of equine piroplasms in Greece with a note on speciation within Theileria genotypes (T. equi and T. equi-like). Infect Genet Evol. 2010;10(7):963-8.

30. Munkhjargal T, Sivakumar T, Battsetseg B, Nyamjargal T, Aboulaila M, Purevtseren B, et al. Prevalence and genetic diversity of equine piroplasms in Tov province, Mongolia. Infect Genet Evol. 2013;16:178-85.

31. Mahmoud MS, El-Ezz NT, Abdel-Shafy S, Nassar SA, El Namaky AH, Khalil WK, et al. Assessment of Theileria equi and Babesia caballi infections in equine populations in Egypt by molecular, serological and hematological approaches. Parasit Vectors. 2016;9:260.

32. Wang J, Liu J, Yang J, Wang X, Li Z, Jianlin X, et al. The first molecular detection and genetic diversity of Babesia caballi and Theileria equi in horses of Gansu province, China. Ticks Tick Borne Dis. 2019;10(3):528-32.

\section{Figures}




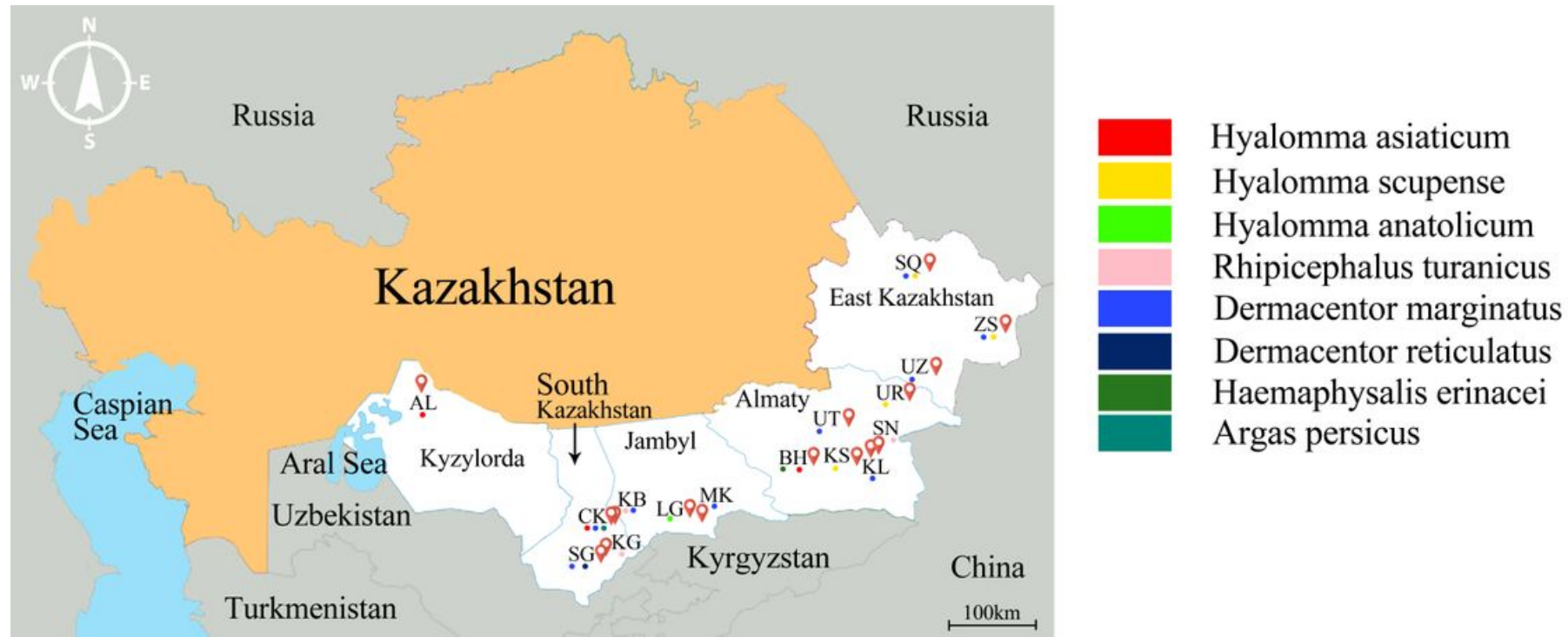

Figure 1

Distribution of tick species sampled in 16 districts of 5 border oblasts in the East and South regions of Kazakhstan. 




\section{Figure 2}

Phylogenic analysis of Babesia spp. and Theileria spp. in ticks collected from five border oblasts of Kazakhstan. The tree was constructed with the Maximum Likelihood method (ML; bootstrap replicates: 1000), using concatenated sequence data of the 18S rRNA gene with MEGA7. Babesia and Theileria

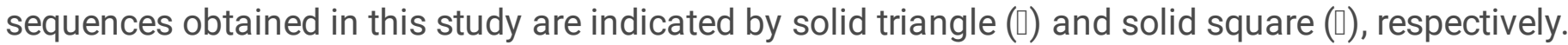




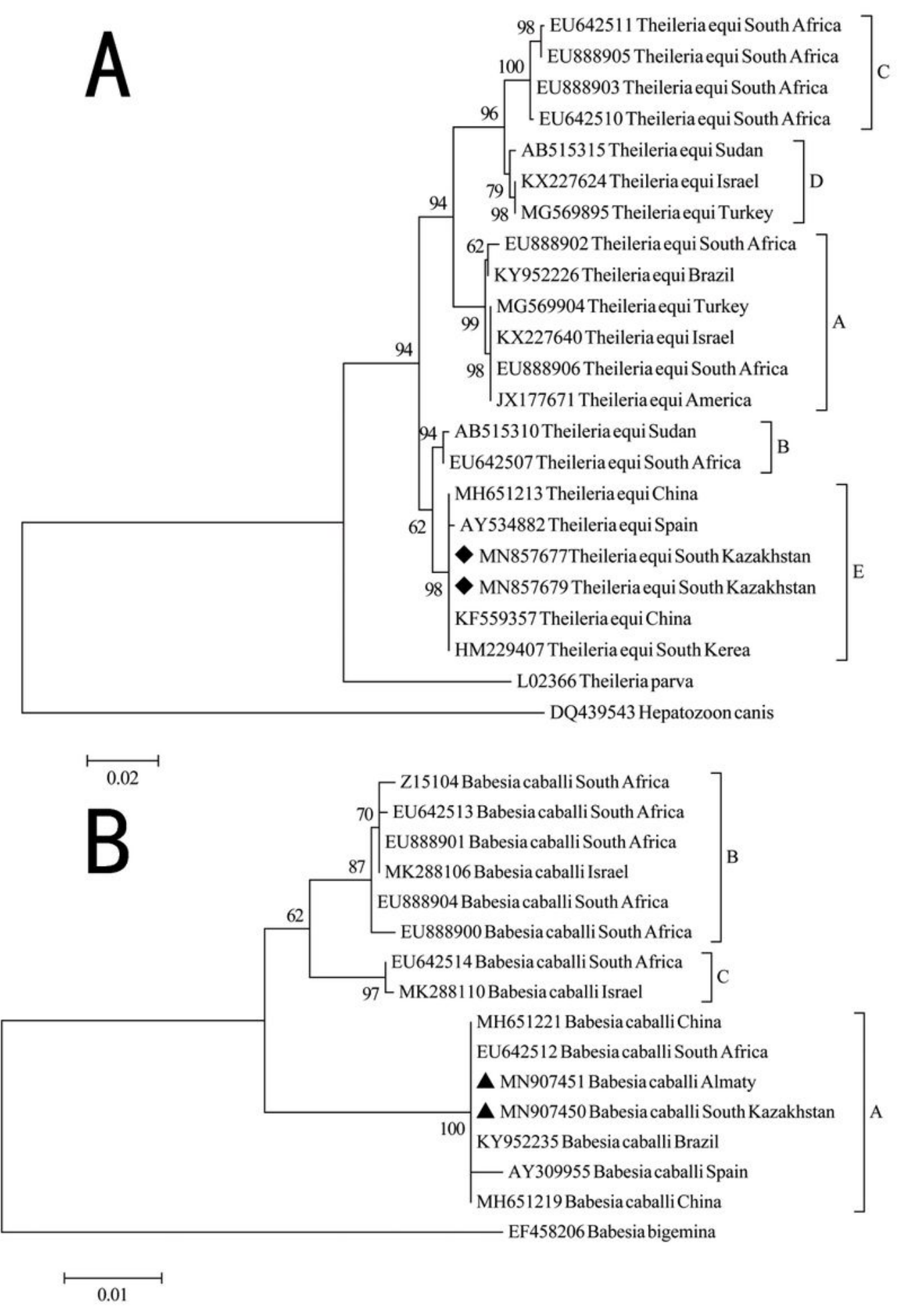

\section{Figure 3}

Phylogenetic tree of T. equi and B. caballi genotype inferred from partial sequences of the $18 \mathrm{~S}$ rRNA gene. A: Genotypic analysis with the sequences of T. equi, B: Genotypic analysis with the sequences of B. caballi. The tree was constructed with the Maximum Likelihood method (ML; bootstrap replicates: 1000), using concatenated sequence data of the 18S rRNA gene with MEGA7. Sequences of T. equi and B. caballi obtained in this study are indicated by solid diamond (\) and solid triangle (₫), respectively. 


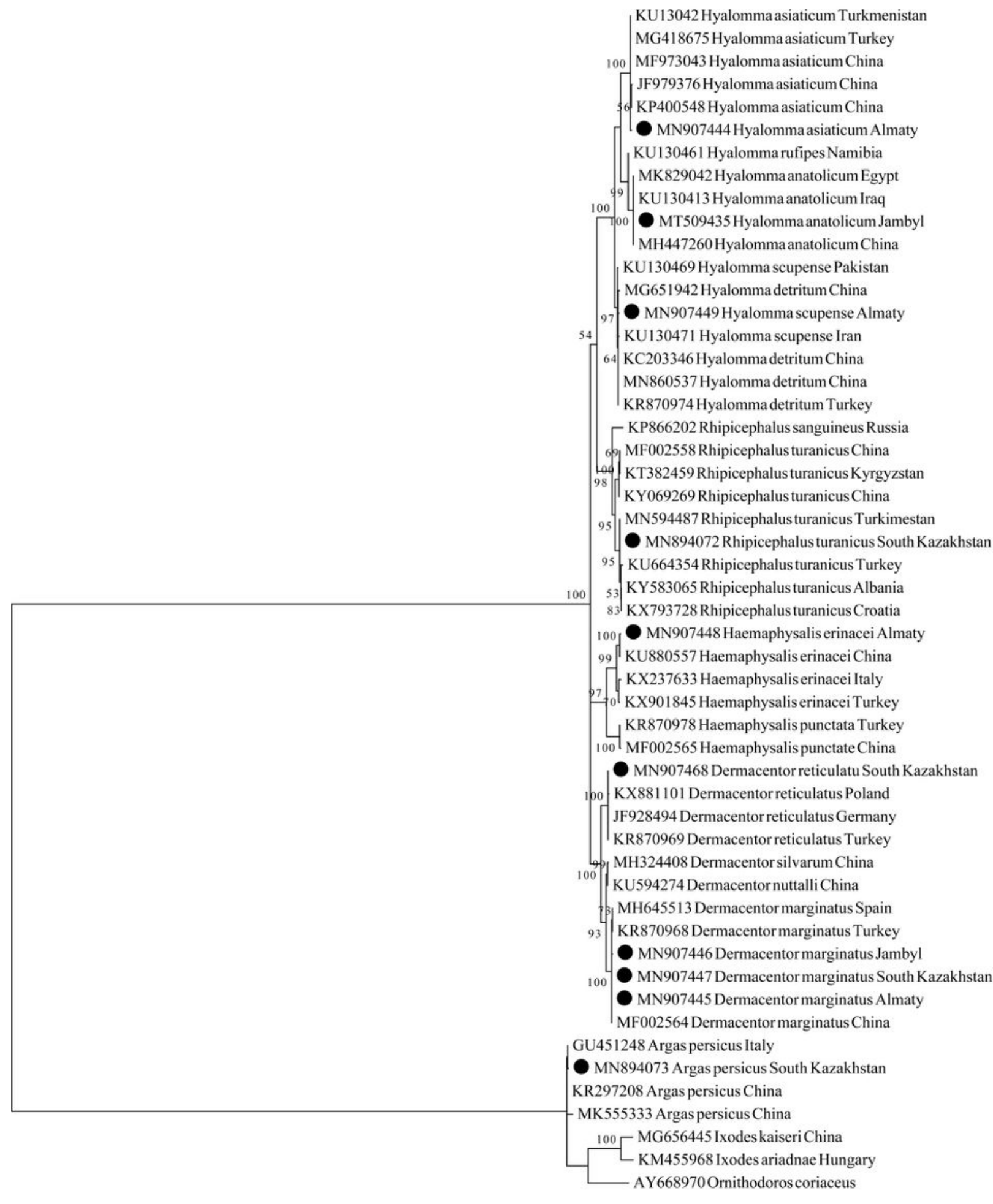

Figure 4

Phylogenic analysis of representative tick specimens: sequences of the tick species obtained in this study are indicated by solid circle ( $\square$ ). The tree was constructed with the Maximum Likelihood method (ML; bootstrap replicates: 1000), using sequence data of the 16S rDNA gene with MEGA7.

\section{Supplementary Files}


This is a list of supplementary files associated with this preprint. Click to download.

- AppendixTableS2.docx

- AppendixTableS1.docx

- AppendixTableS3.docx

- GraphicalAbstract.tif 